\title{
Serological evidence of increased susceptibility to varicella-zoster virus reactivation or reinfection in natalizumab-treated patients with multiple sclerosis
}

Rebekka Kohlmann, Anke Salmen, Andrew Chan, Cornelius Knabbe, Jürgen Diekmann,
Norbert Brockmeyer, Adriane Skaletz-Rorowski, Claudia Michalik, Ralf Gold and Klaus Überla

\section{Abstract}

Background: Serious adverse drug reactions of disease-modifying drugs in multiple sclerosis (MS) therapy may include enhanced susceptibility to reactivation of neurotropic herpes viruses like varicella-zoster virus (VZV) and the John Cunningham (JC) polyomavirus.

Objective: Because symptomatic reactivation of these viruses are rare events, we determined the incidence of rises in anti-VZV IgG antibody levels as a potential marker for enhanced susceptibility to subclinical and symptomatic reactivation of neurotropic viruses.

Methods: Anti-VZV IgG levels were measured in paired serum samples taken 6-8 months apart from natalizumab-treated MS patients, healthy blood donors and human immunodeficiency virus (HIV) infected patients.

Results: The incidence of significant rises in anti-VZV IgG levels in natalizumab-treated MS patients was 4.26 per 100 person-years, which was significantly higher than in healthy blood donors. Retrospective evaluation of the available medical records of patients with rises of anti-VZV IgG levels did not reveal herpes zoster (i.e. shingles) manifestations.

Conclusions: The increased incidence of significant rises of anti-VZV IgG levels in natalizumab-treated MS patients might indicate an association of natalizumab treatment of MS with an elevated risk of a subclinical VZV reactivation and/or reinfection events. Whether this is predictive of an increased risk of herpes zoster or even symptomatic reactivation of other neurotropic viruses remains to be determined in larger prospective studies.

Keywords: Adverse events, antibodies, autoimmune disease, blood donors, herpes zoster, human immunodeficiency virus, immunosuppression, JC virus, multiple sclerosis, natalizumab, neurotropic virus, risk factors, subclinical reactivation, varicella-zoster virus, virus reactivation

Date received: 8 November 2014; date accepted: 17 February 2015

\section{Introduction}

Multiple sclerosis (MS) is a chronic immunemediated disease of the central nervous system (CNS), characterized by inflammatory processes, demyelination and axonal degradation. ${ }^{1}$ MS therapy aims at immunomodulation and/or immunosuppression, including use of established drugs like corticosteroids for relapse treatment; and disease-modifying drugs (DMDs) such as interferon-beta, glatiramer acetate, natalizumab, alemtuzumab, fingolimod, teriflunomide and dimethyl fumarate. ${ }^{2}$ Especially for newer DMDs, regulatory authorities demand observational studies and registries, to detect their possible adverse treatment effects and frequencies.

Natalizumab is a humanized monoclonal IgG4 antibody, targeting $\alpha 4 \beta 1$-integrin (VLA-4) mediated transmigration of activated immune cells from peripheral
Multiple Sclerosis Journal 2015, Vol. 21(14) 1823-1832 DOI: $10.1177 /$ 1352458515576984

(C) The Author(s), 2015. Reprints and permissions: http://www.sagepub.co.uk/ journalsPermissions.nav
Correspondence to: Klaus Überla

Universitätsklinikum Erlangen, Institute of Clinical and Molecular Virology, Schlossgarten 4, 91054 Erlangen. klaus.ueberla@fau.de Rebekka Kohlmann Department of Molecular and Medical Virology, Ruhr-University Bochum, Germany

Anke Salmen Andrew Chan Ralf Gold Department of Neurology, Sankt Josef-Hospital,

Ruhr-University Bochum, Germany

Cornelius Knabbe Jürgen Diekmann Institute of Laboratory and Transfusion Medicine, Heart and Diabetes Centre North Rhine-Westphalia, RuhrUniversity Bochum, Bad Oeynhausen, Germany

Norbert Brockmeyer Adriane Skaletz-Rorowski German Competence Network for HIV/AIDS; Department of Dermatology, Venerology and Allergology; Sankt Josef-Hospital; Ruhr-University Bochum; Germany

Claudia Michalik Clinical Trials Center (ZKS), Cologne, Germany

Klaus Überla Department of Molecular and Medical Virology, Ruhr-University Bochum, Germany/ Universitätsklinikum Erlangen, Institute of Clinical and Molecular Virology, Friedrich-Alexander University ErlangenNürnberg, Erlangen, Germany 
blood into the CNS, by specifically blocking the $\alpha 4$-subunit of VLA-4 on these cells. ${ }^{3}$ In addition, a prolonged increase in peripheral lymphocytes, mainly B cells, has been observed. ${ }^{4}$ Although natalizumab proved to be clinically highly efficacious, its application in MS treatment was hampered by the occurrence of natalizumab-associated cases of progressive multifocal leukoencephalopathy (PML), ${ }^{5}$ a rare but potentially fatal opportunistic CNS infection caused by the John Cunningham virus (JCV). ${ }^{6}$ The overall risk of PML in natalizumab-treated MS patients is 3.41 per 1000 patients, ${ }^{7}$ and screening for anti-JCV antibody status has become clinically routine in natalizumab treatment of MS and for PML risk stratification. ${ }^{8,9}$

Increasing evidence points to a higher risk of herpes virus infections in MS patients treated with novel DMDs. Theoretically, blocking migration of virusspecific T cells by DMDs should reduce the control of herpes simplex virus (HSV) and varicella-zoster virus (VZV) reactivation from persistently-infected spinal root ganglia. The first observational evidence in support of this hypothesis was obtained during clinical trials of fingolimod, ${ }^{10-12}$ a sphingosine-1-phosphate receptor agonist that inhibits lymphocyte emigration from the thymus and peripheral lymphoid organs. ${ }^{13}$ Furthermore, a growing number of case reports are suggestive of an increase in the risk of HSV and VZV infections in MS patients undergoing treatment with fingolimod ${ }^{14}$ and natalizumab. ${ }^{15-21} \mathrm{~A}$ study on functional T-cell analyses in patients treated with fingolimod also shows a slightly reduced antiviral T-cell response with respect to herpes viruses, occasionally accompanied by subclinical reactivation of VZV or Epstein-Barr virus (EBV) in the saliva. ${ }^{22}$ Nevertheless, larger studies defining susceptibility to neurotropic herpesvirus infections in differently treated MS patients, in comparison to healthy people, are missing. Such comparative analyses are hampered by the fact that the incidence of clinicallyrelevant herpesvirus infections is low, demanding investigation of large patient cohorts to reach statistical significance. This limitation could possibly be overcome, if not only the symptomatic, but also the subclinical infections were monitored.

VZV is a common herpesvirus, with a seroprevalence rate of nearly $100 \% .{ }^{23}$ After primary infection, VZV latently persists in spinal root ganglia. The decline of VZV-specific cellular immune responses leads to reactivation of the virus and can result in herpes zoster. In addition, evidence for reinfection events has been obtained (reviewed in Quinlivan and Breuer). ${ }^{24}$

The incidence of herpes zoster in the general population is $0.3-0.5$ per 100 person-years, independent of gender but sharply increasing with age, up to $0.6-0.8$ per 100 person-years in individuals aged 50-80 years. ${ }^{25}$ Besides age dependency, incidence increases with certain conditions that impair cell-mediated immunity, for example infection with human immunodeficiency virus (HIV), leading to an incidence of 2.9-5.1 per 100 person-years in HIV-infected patients, prior to the introduction of highly-active antiretroviral therapy; and $0.9-1.7$ per 100 person-years in the current antiretroviral therapy era. ${ }^{26,27}$

We performed statistical simulations, assuming a base-line incidence of herpes zoster in healthy people of 0.003 per person-year and a hypothetical $50 \%$ increase in herpes zoster incidence in MS patients treated with novel DMDs. These simulations indicated that 64,913 person-years of follow-up would be required per patient group to observe a relative risk (RR) of 1.5 at a global significance level of 0.05 , with a power of 0.8 . Since asymptomatic VZV reactivations or reinfections, as detected by significant rises of anti-VZV IgG levels, appear to be more frequent than herpes zoster in non-immunosuppressed individuals ${ }^{28}$; we compared the incidence of significant rises of anti-VZV IgG levels in natalizumab-treated MS patients to control groups, to gather serological evidence of enhanced susceptibility to VZV reactivation or reinfection. This approach could offer the opportunity to measure susceptibility to VZV reactivation or reinfection in smaller patient groups.

\section{Materials and methods}

\section{Patients and samples}

This non-concurrent cohort study was approved by the responsible local ethics committee (Ruhr-University Bochum, in Bochum, Germany; reg. no. 4862-13).

Table 1 shows the study's paired serum samples, collected for other reasons (i.e. monitoring of disease, therapy or blood donation) and stored frozen at $-20^{\circ} \mathrm{C}$ to $-80^{\circ} \mathrm{C}$, that were available for analysis.

Nat-MS group. Paired sera of 205 natalizumabtreated MS patients; with an interval between the first and second sampling of 8.3 months, on average (median: 7.5 months; range: 4.0-17.79 months; standard deviation (SD): 2.5 months; and cumulative observation period: 141 person-years), with both time-points of sampling during natalizumab treatment; collected between 2007 and 2011 in a laboratory for nationwide anti-natalizumab antibody testing (Department of Neurology, Sankt Josef-Hospital, Ruhr-University Bochum, Bochum, Germany). 
Table 1. Baseline characteristics of study groups and incidence of significant rises of anti-VZV IgG levels.

\begin{tabular}{|c|c|c|c|}
\hline & Natalizumab-treated & Healthy & HIV-infected \\
\hline & MS patients $n=205$ & blood donors $n=402$ & Patients $n=95$ \\
\hline \multicolumn{4}{|l|}{ Clinical data } \\
\hline Mean age (yrs) & 37.20 & 36.37 & 44.40 \\
\hline \multicolumn{4}{|l|}{ Age distribution (\%) } \\
\hline $10.0-19.9$ yrs & 4.39 & 4.23 & 0.00 \\
\hline $20.0-29.9 \mathrm{yrs}$ & 22.93 & 26.62 & 7.37 \\
\hline $30.0-39.9 \mathrm{yrs}$ & 34.63 & 31.84 & 26.32 \\
\hline $40.0-49.9$ yrs & 25.37 & 25.87 & 41.05 \\
\hline $50.0-59.9$ yrs & 12.20 & 11.44 & 17.89 \\
\hline $60.0-69.9$ yrs & 0.49 & 0.00 & 7.37 \\
\hline \multicolumn{4}{|l|}{ Gender $(\%)$} \\
\hline Female & 73.17 & 71.89 & 15.79 \\
\hline Male & 26.83 & 28.11 & 84.21 \\
\hline \multirow{2}{*}{ CD4 cell counts $(\%)$} & NA & NA & $<200 / \mu \mathrm{l}: 7.37$ \\
\hline & & & $\begin{array}{l}200-<500 / \mu \mathrm{l}: 50.53 \\
\geqslant 500 / \mu \mathrm{l}: 42.11\end{array}$ \\
\hline Anti-VZV IgG seropositivity rate (\%) & 99.02 & 98.76 & 96.84 \\
\hline \multicolumn{4}{|l|}{ Observation period per individual } \\
\hline Mean (months) & 8.25 & 6.46 & 7.08 \\
\hline Median (months) & 7.47 & 6.00 & 6.97 \\
\hline Range (months) & $3.97-15.73$ & $5.00-11.00$ & $5.73-9.00$ \\
\hline SD (months) & $+/-2.50$ & $+/-1.25$ & $+/-0.83$ \\
\hline \multicolumn{4}{|l|}{ Cumulative observation period } \\
\hline (yrs) & 140.86 & 216.42 & 56.04 \\
\hline \multicolumn{4}{|c|}{ Incidence of significant (4-fold or higher) rise of anti-VZV IgG antibody levels } \\
\hline Total frequency (absolute $n$ ) & 6 & 0 & 0 \\
\hline Incidence per 100 patients (absolute $n$ ) & 2.93 & $<0.25$ & $<1.05$ \\
\hline Incidence in 100 person-yrs (absolute $n$ ) & 4.26 & $<0.46$ & $<1.79$ \\
\hline
\end{tabular}

HD group. Paired sera of 402 healthy blood donors (HD), with an interval between the first and second sampling of 6.5 months on average (median: 6.0 months; range: $5.0-11.0$ months; SD: 1.25 months; cumulative observation period: 216 person-years); collected in 2006 at the Institute of Laboratory and Transfusion Medicine (Heart and Diabetes Centre of North Rhine-Westphalia, Ruhr-University Bochum, Bad Oeynhausen, Germany).

HIV group. Paired sera of 95 HIV-infected patients, with an interval between first and second sampling of 7.1 months, on average (median: 7.0 months; range: 5.7-9.0 months; SD: 0.8 months; cumulative observation period: 56 person-years); and collection between 2005 and 2007 at the German Competence Network for HIV/AIDS (Department of Dermatology, Venerology and Allergology; Saint Josef-Hospital; Ruhr-University Bochum; Bochum; Germany).
Controls. The HD group and the HIV group served as controls: For the HD group, stored serum pairs were selected and age- and gender-matched as accurately as possible to the Nat-MS group. For the HIV group, age- and gender-matching was not possible with the available samples. Clinical data from patients who had had significant rises in anti-VZV IgG levels were obtained by review of their medical records.

\section{Antibody detection}

For all paired serum samples, anti-VZV IgG levels were quantitatively determined using the SERION ELISA Classic VZV IgG Kit (VirionlSerion, Würzburg, Germany). A rise in anti-VZV IgG antibody levels of 4-fold or higher was assessed as significant, as is widely accepted,,$^{29,30}$ and was counted per patient group. In case of a significant rise, expanded antibody detection was performed using 
further SERION ELISA Classic kits, including tests for IgM responses. Overall IgG levels were determined by nephelometry in a commercial clinical laboratory.

\section{Statistical analysis}

Testing for equality of populations with regard to the incidence of significant rises of anti-VZV IgG antibody reactivity was performed with Fisher's exact test, at a global significance level of 0.05 . We did an adjustment of significance level for the multiplicity of tests, using the Holm-Bonferroni correction.

\section{Results}

Paired serum samples of 205 natalizumab-treated MS patients (Nat-MS group), 402 healthy blood donors (HD group) and 95 HIV-infected patients (HIV group) were analysed for anti-VZV IgG levels. Baseline characteristics (age and gender distribution; observation period per individual, i.e. intervals of paired serum samples, and cumulative observation period; and for HIV-infected patients, additional CD4 cell count distribution as a marker of immune status) per group are shown in Table 1. Due to the retrospective approach, the observation period per individual was slightly different per group, namely $8.3+/-2.5$ months for the Nat-MS group, $6.5+/-1.3$ months for the HD group and $7.1+/-0.8$ months for the HIV group, respectively. This minor difference in observation periods should not affect the conclusions drawn from this study, since anti-VZV IgG levels are stable over years. ${ }^{28}$

For healthy blood donors, age- and gender-matching to natalizumab-treated MS patients was performed (Table 1); however, the epidemiology of MS and HIV infection reflected in the composition of the respective national disease networks is highly divergent in Germany also leading to differences in gender distribution. ${ }^{31,32}$ Thus, the HIV group differed from the Nat-MS group, as we received samples representative of the composition of the German Competence Network for HIV/AIDS.

Overall, we observed a VZV seropositivity rate of 97-99\%. In 205 natalizumab-treated MS patients, we detected six significant rises of anti-VZV IgG levels over a cumulative observation period of 141 personyears. As a consequence, the incidence rate was 2.93 per 100 patients and 4.26 per 100 person-years (Table 1 and Figure 1). In contrast, no significant rises of anti-VZV IgG levels were detected in both our control groups (HD and HIV), indicating an incidence of $<$ 0.46 per 100 person-years for the HD group (216 cumulative observation years) and $<1.79$ per 100 person-years for the HIV group (56 cumulative observation years), respectively. Thus, significant rises of anti-VZV IgG levels occurred at least 9.3-fold and 2.4-fold more frequently in the study's natalizumabtreated MS patients, compared to healthy blood donors and HIV patients, respectively.

The incidence of significant rises of anti-VZV IgG levels per 100 person-years in the Nat-MS group differed significantly from the one in the HD group $(p=$ 0.0036, at a Bonferroni-Holm-adjusted significance level of 0.0167 , corresponding to a global significance level of 0.05 ). We did not observe a statistically significant difference between the Nat-MS group and the HIV group $(p=0.1303)$, presumably due to the smaller size of the HIV group.

For the six patients with a significant rise of the anti-VZV IgG levels, additional laboratory tests were performed (Table 2). Determination of antiVZV IgM antibody levels showed negative results, arguing against primary VZV infections. To exclude a potential polyclonal B-cell activation, which may also lead to rises of antibody levels, we determined anti-cytomegalovirus (CMV) IgG, anti-HSV IgG and overall IgG levels. The overall IgG levels remained stable within the normal range for all six patients, with a slight increase in three cases (maximum: 1.4-fold) and a slight decrease in the other three cases. There was no significant rise of anti-CMV nor anti-HSV IgG levels in patients with anti-CMV IgG positive (Nat-MS no. 76 ) or anti-HSV IgG positive first serum samples (Nat-MS nos. 55, 58 and 197); however, seroconversion for anti-HSV IgG occurred in two of the initial anti-HSV IgG negative samples (Nat-MS nos. 33 and 76) and the second samples from these patients also became positive for anti-HSV IgM.

For four of the six patients with a significant rise of anti-VZV IgG antibody levels, additional clinical data could be obtained (Table 2). Interestingly, none of these four patients developed herpes zoster or other clinical manifestations of VZV infection during the time interval from the first to the second serum sampling. We also screened medical records for potential confounding factors during this time interval, including application of immunosuppressive or immunomodulatory drugs other than natalizumab, VZV vaccination and the existence of diseases leading to immunosuppressive conditions other than MS. Confounding factors were excluded in three of four cases; while in one case, the patient had received steroid pulse therapy during the observation period. 


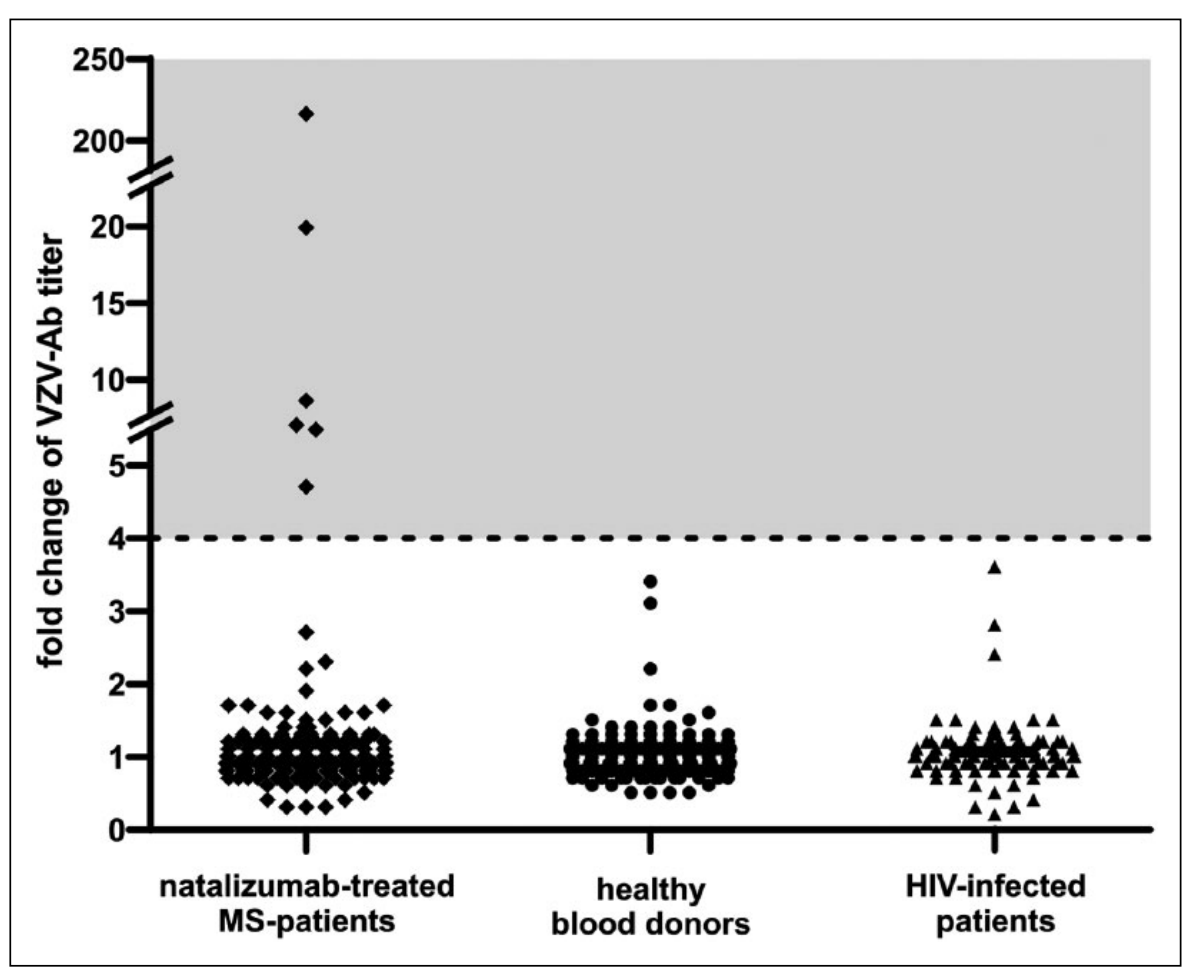

Figure 1. Fold changes in anti-VZV IgG levels.

We determined the anti-VZV IgG levels of natalizumab-treated MS patients, healthy blood donors and HIV-infected patients at baseline and after 6-8 months, using ELISA. The change in antibody level is given as ratio of values at the second and first serum sampling points (black symbols, 1 per paired serum sample). A significant rise of 4-fold or higher (highlighted by grey background) of anti-VZV IgG antibody levels indicated there was a VZV reactivation or VZV reinfection, comprising both symptomatic and subclinical events. While six natalizumab-treated MS patients $(n=205)$ showed a significant rise of anti-VZV antibody levels, no significant rise occurred in the HC group $(n=402)$ nor HIV group $(n=95)$.

ELISA: enzyme-linked immunosorbent assay; HC: healthy control; HIV: human immunodeficiency virus; IgG: immunoglobulin or antibody Type G; MS: multiple sclerosis; VZV: varicella-zoster virus

\section{Discussion}

As the incidence of clinically-relevant neurotropic herpesvirus infections is low, studies for defining susceptibility to these infections in differently-treated MS patients require large patient cohorts to reach statistical significance. To overcome this limitation, we intended to implement serological detection of herpesvirus infections using a significant rise in IgG levels, in serial serum samples, as a diagnostic criterion; supposing that susceptibility to herpesvirus infections can be measured with higher sensitivity by a serologic follow-up than by a clinical follow-up. We chose to monitor with anti-VZV IgG antibodies, because of their high seroprevalence and because of the notion that VZV reactivation, in contrast to HSV reactivation, ${ }^{33}$ is frequently accompanied by significant rises of anti-VZV IgG levels.

Although the use of rises of anti-VZV IgG levels may be limited for the diagnosis of herpes zoster, due to the fact that the first serum sample is taken too late after the onset of a rash, ${ }^{34}$ this should not bias the present study, as our serum samples were taken independently of clinical symptoms of herpes zoster. We assessed rises of 4-fold or higher as significant, which is in line with recommendations. ${ }^{29,30}$ Whereas significant rises occur in about $85 \%$ of herpes zoster cases, ${ }^{35,36}$ the magnitude and duration of the antibody responses vary individually. Interestingly, higher antibody titers seem to be associated with increased herpes zoster severity; and therefore, also correlate with age. ${ }^{37}$ In general, anti-VZV antibody levels increase rapidly after a herpes zoster onset, reaching multifold higher values at week 3 (about 15-fold higher compared to pre-rash values and 5-fold higher, compared to values at 1 week in unvaccinated individuals), decreasing at week 6 and over the following months, and plateau during the next 2 years. ${ }^{37}$

The observed VZV seropositivity rate of $97-99 \%$ was within the previously-published range. ${ }^{23}$ In the natalizumab-treated MS patients, a strikingly high incidence of significant rises of anti-VZV IgG levels was observed: 4.26 cases per 100 person-years. This opens 
Table 2. Overview of the six individuals with a significant rise of anti-VZV IgG levels.

\begin{tabular}{|c|c|c|c|c|c|c|}
\hline Group and Patient number & $\begin{array}{l}\text { Nat-MS } \\
\text { no. } 33\end{array}$ & $\begin{array}{l}\text { Nat-MS } \\
\text { no. } 55\end{array}$ & $\begin{array}{l}\text { Nat-MS } \\
\text { no. } 58\end{array}$ & $\begin{array}{l}\text { Nat-MS } \\
\text { no. } 76\end{array}$ & $\begin{array}{l}\text { Nat-MS } \\
\text { no. } 173\end{array}$ & $\begin{array}{l}\text { Nat-MS } \\
\text { no. } 197\end{array}$ \\
\hline Gender & M & M & $\mathrm{F}$ & $\mathrm{F}$ & $\mathrm{F}$ & $\mathrm{F}$ \\
\hline Age (yrs) & 16.5 & 30.8 & 29.0 & 25.4 & 25.6 & 25.4 \\
\hline Observation period (months) & 14.5 & 10.3 & 13.9 & 8.5 & 6.7 & 8.0 \\
\hline \multicolumn{7}{|l|}{ Anti-VZV IgG $(\mathrm{mIU} / \mathrm{ml})^{\mathrm{a}}$} \\
\hline $1^{\text {st }}$ sample & 384 & 594 & 118 & 997 & 1032 & 192 \\
\hline $2^{\text {nd }}$ sample & 7660 & 128,500 & 828 & 4670 & 6950 & 1656 \\
\hline \multicolumn{7}{|l|}{ Anti-VZV IgM ${ }^{b}$} \\
\hline $1^{\text {st }}$ sample & neg & neg & neg & neg & neg & neg \\
\hline $2^{\text {nd }}$ sample & neg & neg & neg & neg & neg & neg \\
\hline \multicolumn{7}{|l|}{ Anti-HSV IgG $(\mathrm{U} / \mathrm{ml})^{\mathrm{c}}$} \\
\hline $1^{\text {st }}$ sample & neg & 797 & 514 & neg & neg & 251 \\
\hline $2^{\text {nd }}$ sample & 239 & 872 & 531 & 122 & neg & 237 \\
\hline \multicolumn{7}{|l|}{ Anti-HSV IgM ${ }^{b}$} \\
\hline $1^{\text {st }}$ sample & neg & neg & pos & neg & neg & neg \\
\hline $2^{\text {nd }}$ sample & pos & neg & pos & pos & neg & neg \\
\hline \multicolumn{7}{|l|}{ Anti-CMV IgG (PEI-U/ml)d } \\
\hline $1^{\text {st }}$ sample & neg & neg & neg & 240 & neg & neg \\
\hline $2^{\text {nd }}$ sample & neg & neg & neg & 252 & neg & neg \\
\hline \multicolumn{7}{|l|}{ Overall IgG $(\mathrm{mg} / \mathrm{dl})^{\mathrm{e}}$} \\
\hline $1^{\text {st }}$ sample & 1090 & 1430 & 766 & 1310 & 1220 & 610 \\
\hline $2^{\text {nd }}$ sample & 925 & 1400 & 874 & 1550 & 1140 & 840 \\
\hline $\begin{array}{l}\text { Herpes zoster manifested during } \\
\text { observation period }\end{array}$ & no & no & NA & NA & no & no \\
\hline \multicolumn{7}{|l|}{$\begin{array}{l}\text { Potential confounding factors } \\
\text { during observation period }\end{array}$} \\
\hline VZV vaccination & no & no & NA & NA & no & no \\
\hline Relapse therapy & no & no & NA & NA & no & yes $^{f}$ \\
\hline $\begin{array}{l}\text { Other diseases that lead to } \\
\text { conditions of immunosuppression }\end{array}$ & no & no & NA & NA & no & no \\
\hline
\end{tabular}

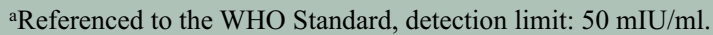

${ }^{\mathrm{b}} \mathrm{Qualitative}$ assay, detection limit: $10 \mathrm{U} / \mathrm{ml}$ for anti-VZV IgM and $20 \mathrm{U} / \mathrm{ml}$ for anti-HSV IgM.

'Referenced to a standard serum provided by the instructor, detection limit: $20 \mathrm{U} / \mathrm{ml}$.

${ }^{\mathrm{d}}$ Referenced to the national CMV IgG reference serum of the Paul Ehrlich Institute (Germany), detection limit: 25 PEI-U/ml.

eNormal range for adults: $700-1600 \mathrm{mg} / \mathrm{dl}$.

fPatient received steroid pulse therapy before the first and second sampling.

CMV: cytomegalovirus; dl: decilitre; F: female gender; HSV: herpes simplex virus; Ig: antibody or immunoglobulin of type G or M;

IU: international units; M: male gender; ml: mililiters; MS: multiple sclerosis; NA: data not available; Nat: natalizumab; PEI: Paul

Ehrlich Institute; VZV: varicella-zoster virus; WHO: World Health Organisation; yrs: years

the possibility of comparing the incidence of such rises in MS patients treated with different DMDs, to explore potential differences between drug regimens. In addition, the incidence of significant rises of antiVZV IgG levels was at least 9.3-fold higher than in age- and gender-matched healthy blood donors, suggesting that in natalizumab-treated MS patients, the immune control of VZV is reduced and the risk of viral reactivation enhanced. If this proposed higher susceptibility of natalizumab-treated MS patients to VZV is confirmed in further studies, this might have therapeutic consequences, e.g. VZV vaccination in the case of seronegativity, as is already recommended for fingolimod treatment, or acyclovir prophylaxis, as already recommended for alemtuzumab treatment.

Potential confounding factors which might lead to increased susceptibility to VZV in natalizumab-treated MS patients were also considered by screening the patients' medical records (immunosuppressive conditions other than MS, immunosuppressive or immunomodulatory treatment besides natalizumab or VZV 
vaccination during the observation period). While we could exclude these confounding factors in three of the four cases for which clinical data were available, one patient received steroid pulse therapy in addition to natalizumab treatment during the observation period, which may have contributed to the VZV reactivation or reinfection in this patient. Furthermore, two of the six rises in anti-VZV IgG antibody levels were accompanied by a seroconversion of anti-HSV IgM and IgG antibodies. As up to one-third of all primary HSV infections show a heterotypic antibody response to $\mathrm{VZV},{ }^{30}$ the rise of anti-VZV IgG levels in these two patients may be attributable to a primary HSV infection, rather than reactivation of or reinfection with VZV.

Because primary HSV infections leading to significant rises of anti-VZV IgG antibody levels were not observed in the HD group, this may also suggest an increased exposure or susceptibility of natalizumabtreated MS patients to HSV; however, a recent primary VZV infection can be excluded, as the six patients with a significant rise of the anti-VZV IgG levels were antiVZV IgM negative, whereas IgM is detectable in 100\% of convalescent sera from patients with varicella, for about 3 months from the onset of the illness. ${ }^{34}$ In herpes zoster cases, anti-VZV IgM can be found in $30-40 \%$, usually with lower magnitude and shorter duration, ${ }^{35,36}$ implying that the negative IgM results observed in our study do not rule out VZV reactivation nor reinfection, especially as serum samples were taken independently of clinical symptoms of herpes zoster. Besides, a positive IgM test could not have been used to distinguish reliably between primary and recurrent VZV infection. In addition, polyclonal B-cell activation could theoretically account for the rise of anti-VZV IgG levels, because the number of immune cells and particularly $B$ cells in peripheral blood was shown to increase under natalizumab treatment, as a result of leucocyte transmigration inhibition and/or lymphocyte release from the bone marrow. ${ }^{4}$ Nevertheless, for the six patients with a significant rise of the anti-VZV IgG levels, a general polyclonal B-cell activation is unlikely, as there was no significant increase in overall $\mathrm{IgG}$ levels.

Although there are a number of case reports suggesting overrepresentation of symptomatic HSV and VZV infections in natalizumab-treated MS patients, ${ }^{15-21}$ valid data on the incidence of symptomatic HSV or VZV reactivation in MS patients with and without natalizumab treatment are not available; therefore, it is presently not possible to link the increased incidence of significant rises of anti-VZV IgG levels with an increased risk of symptomatic VZV reactivation or reinfection. At least for four of the six patients, the rise of anti-VZV IgG levels was not accompanied by herpes zoster nor other clinical symptoms of VZV disease, indicating subclinical reactivation or reinfection in these cases. Evidence of subclinical reactivation of VZV was previously obtained by measuring significant rises of anti-VZV IgG levels after household exposure of seropositive individuals (reviewed in Quinlivan and Breuer) ${ }^{24}$; by detection of VZV DNA, in patients with malignancies without clinical symptoms of VZV disease ${ }^{38}$; and by intrathecal synthesis of anti-VZV antibodies in the absence of a history of herpes zoster, in HIV-infected individuals. ${ }^{39}$

In a long-term longitudinal study, with a follow-up of 45 healthy subjects for up to 26 years, it was observed that there were rises of anti-VZV antibody levels by more than 2-fold, with an incidence of 1.6 events per 100 person-years. ${ }^{28}$ This incidence is about 4 -fold lower than the incidence of at least a 2-fold rise in anti-VZV antibody levels that we observed in the Nat-MS group (6.39 per 100 person-years). Interestingly, only $20 \%$ of antibody titer increases were accompanied by a clinical manifestation of herpes zoster, ${ }^{28}$ indicating a higher sensitivity of serologic follow-up, as compared to clinical follow-up, for determining the rate of VZV reactivation or reinfection events and supporting our approach.

Despite an increased risk of herpes zoster in HIVinfected patients, we did not detect rises of anti-VZV IgG levels in this group. Probably this finding is attributed to the comparably small group size $(n=95)$ : Because we cover a cumulative observation period of only 56 person-years, our finding corresponds to an incidence of $<1.79$ per 100 person-years, which is still in line with the literature reporting herpes zoster incidences of $0.9-1.7$ per 100 person-years in the current antiretroviral therapy era. ${ }^{26,27}$ Furthermore, we cannot exclude that a pronounced immunodeficiency in this group may blunt rises of anti-VZV IgG levels, in response to VZV reactivation.

One limitation of this study was its retrospective approach, which restricted the selection of study groups to the availability of stored serum samples. Hence, we compared natalizumab-treated MS patients to healthy blood donors and HIV-infected patients, while untreated MS patients and MS patients under other treatment regimens could not be tested, so far: Further studies are required to finally answer the question whether the observed higher frequency of anti-VZV antibody increases in natalizumab-treated MS patients, in comparison to healthy blood donors, is attributed to MS disease or to natalizumab treatment. Additionally, for further comparison, patients with immunosuppressive or immunomodulatory treatment for other autoimmune 
diseases (e.g. inflammatory bowel disease or rheumatoid arthritis) should be included.

In conclusion, our data from a retrospective natalizumab-treated MS cohort add to the growing notion that natalizumab treatment of MS might be associated with an elevated risk of VZV reactivation or reinfection. Monitoring of anti-VZV IgG levels could be a useful tool to determine and compare susceptibility to VZV reactivation and reinfection, in different patient groups, with higher sensitivity than by monitoring of symptomatic VZV infections. Additional studies confirming the expected correlation between the incidence of significant rises of anti-VZV IgG levels and the risk of symptomatic herpes zoster are warranted.

\section{Acknowledgements}

We thank Heike Seidenstuecker for excellent technical assistance and Hans J Trampisch of the Department of Medical Statistics at the RuhrUniversity Bochum for advice concerning our statistical analyses. The Competence Network for HIV/AIDS thanks the German Federal Ministry of Education and Research for its financial support from 2002-2011.

\section{Conflict of interest}

Authors RK, CK, JD, AS-R, CM and KÜ declare that they have no potential conflicts of interest.

AS has received personal compensation for activities with Sanofi and Almirall Hermal GmbH.

$\mathrm{AC}$ has received personal compensation for activities with Almirall Hermal GmbH, Bayer Schering, Biogen Idec, Merck Serono, Novartis and Teva Neuroscience; research support from Bayer Schering, Biogen Idec, Merck Serono and Novartis; and research grants from the German Ministry for Education and Research (BMBF, German Competence Network Multiple Sclerosis (KKNMS), CONTROL MS, 01GI0914).

NB had personal compensation for activities from: Bristol-Myers-Squibb, Gilead, ViiV Healthcare, MSD Sharp \& Dohme, Janssen-Cilag and Sanofi Pasteur.

$\mathrm{RG}$ has received personal compensation for activities from Bayer Healthcare, Biogen Idec and Teva Neuroscience; personal compensation for an editorial capacity, from Therapeutic Advances in Neurological Disorders; patent payments from Biogen Idec; and research support from Bayer Healthcare, Biogen Idec, Merck Serono, Teva Neuroscience, Novartis and the German Ministry for Education and Research (BMBF, KKNMS, CONTROL MS, 01GI0914).

\section{Funding}

This work was supported by institutional resources and a grant from Novartis Germany. The Competence Network for HIV/AIDS was supported by the German Federal Ministry of Education and Research during 2002-2011 (grant no. BMBF-01 KI 0501).

\section{Notes}

1. Authors RK and AS contributed equally to this work.

2. The following documenting sites in Germany contributed data to the KompNet cohort: Gemeinschaftspraxis Driesener Straße, Berlin; Gemeinschaftspraxis Mehringdamm, Berlin; Gemeinschaftspraxis Turmstraße, Berlin; Gemeinschaftspraxis Fuggerstraße, Berlin; Praxiszentrum Kaiserdamm, Berlin; Universitätsklinikum Benjamin Franklin, Charité, Berlin; Dermatologische Klinik, Ruhr-Universität, Bochum; Universitätsklinikum, Dortmund; Universitätsklinikum, Düsseldorf; Medizinische Klinik 3, Universitätsklinikum, Erlangen; Klinik für Dermatologie, Universitätsklinikum, Essen; HIVCENTER, Universitätsklinikum, Frankfurt; Ifi-Institut, Hamburg; ICH Grindelpraxis, Infektionsepidemiologisches Zentrum, Hamburg; Medizinische Hochschule, Hannover; Praxis Georgstraße, Hannover; Gemeinschaftspraxis, Kriegsstraße, Karlsruhe, Städtisches Krankenhaus Kemperhof, Koblenz; Praxis Hohenstaufenring, Köln; Gemeinschaftspraxis Isartorplatz, München; MVZ Karlsplatz, HIV Research and Clinical Centre, München; Praxisgemeinschaft Franz Joseph-Straße, München; Klinikum, Osnabrück; and Gemeinschaftspraxis Ulmer/ Frietsch/Müller, Stuttgart.

\section{References}

1. Hafler DA, Slavik JM, Anderson DE, et al. Multiple sclerosis. Immunol Rev 2005; 204: 208-231.

2. Wingerchuk DM and Carter JL. Multiple sclerosis: Current and emerging disease-modifying therapies and treatment strategies. Mayo Clin Proc 2014; 89: $225-240$.

3. Rice GP, Hartung HP and Calabresi PA. Anti-alpha-4 integrin therapy for multiple sclerosis: Mechanisms and rationale. Neurology 2005; 64: 1336-1342.

4. Koudriavtseva T, Sbardella E, Trento E, et al. Long-term follow-up of peripheral lymphocyte subsets in a cohort of multiple sclerosis patients treated with natalizumab. Clin Exp Immunol 2014; 176: $320-326$. 
5. Bloomgren G, Richman S, Hotermans C, et al. Risk of natalizumab-associated progressive multifocal leukoencephalopathy. N Engl J Med 2012; 366: 1870-1880.

6. Tavazzi E, White MK and Khalili K. Progressive multifocal leukoencephalopathy: Clinical and molecular aspects. Rev Med Virol 2012; 22: 18-32.

7. Biogen Idec. PML-Inzidenz unter Tysabri ${ }^{\circledR}$ nach Marktzulassung. Patientenregister, www.tysabri.de. (2013, accessed 30 September 2013).

8. Gorelik L, Lerner M, Bixler S, et al. Anti-JC virus antibodies: Implications for PML risk stratification. Ann Neurol 2010; 68: 295-303.

9. Trampe AK, Hemmelmann C, Stroet A, et al. Anti-JC virus antibodies in a large German natalizumabtreated multiple sclerosis cohort. Neurology 2012; 78 : 1736-1742.

10. Cohen JA, Barkhof F, Comi G, et al. Oral fingolimod or intramuscular interferon for relapsing multiple sclerosis. N Engl J Med 2010; 362: 402-415.

11. Kappos L, Radue EW, O'Connor P, et al. A placebocontrolled trial of oral fingolimod in relapsing multiple sclerosis. $N$ Engl J Med 2010; 362: 387-401.

12. Calabresi PA, Radue EW, Goodin D, et al. Safety and efficacy of fingolimod in patients with relapsingremitting multiple sclerosis (FREEDOMS II): A double-blind, randomised, placebo-controlled, Phase 3 trial. Lancet Neurol 2014; 13: 545-556.

13. Matloubian M, Lo CG, Cinamon G, et al. Lymphocyte egress from thymus and peripheral lymphoid organs is dependent on $\mathrm{S} 1 \mathrm{P}$ receptor 1. Nature 2004; 427: 355-360.

14. Ratchford JN, Costello K, Reich DS, et al. Varicellazoster virus encephalitis and vasculopathy in a patient treated with fingolimod. Neurology 2012; 79: 2002-2004.

15. Fine AJ, Sorbello A, Kortepeter C, et al. Central nervous system herpes simplex and varicella zoster virus infections in natalizumab-treated patients. Clin Infect Dis 2013; 57: 849-852.

16. Shenoy ES, Mylonakis E, Hurtado RM, et al. Natalizumab and HSV meningitis. J Neurovirol 2011; 17: $288-290$

17. Yeung J, Cauquil C, Saliou G, et al. Varicella-Zoster Virus acute myelitis in a patient with MS treated with natalizumab. Neurology 2013; 80: 1812-1813.

18. Fragoso YD, Brooks JB, Gomes S, et al. Report of three cases of herpes zoster during treatment with natalizumab. CNS Neurosci Ther 2013; 19: 280-281.

19. Kwiatkowski A, Gallois J, Bilbault N, et al. Herpes encephalitis during natalizumab treatment in multiple sclerosis. Mult Scler 2012; 18: 909-911.
20. Bourre B, Lefaucheur R, Ahtoy P, et al. Varicellazoster virus acute myelitis in a patient with MS treated with natalizumab. Neurology 2013; 81: 1966-1967.

21. Kobeleva X, Wegner F, Brunotte I, et al. Varicella zoster-associated retinal and central nervous system vasculitis in a patient with multiple sclerosis treated with natalizumab. J Neuroinflamm 2014; 11: 19.

22. Ricklin ME, Lorscheider J, Waschbisch A, et al $\mathrm{T}$-cell response against varicella-zoster virus in fingolimod-treated MS patients. Neurology 2013; 81: 174-181.

23. Wutzler P, Farber I, Wagenpfeil S, et al. Seroprevalence of varicella-zoster virus in the German population. Vaccine 2001; 20: 121-124.

24. Quinlivan M and Breuer J. Molecular studies of varicella zoster virus. Rev Med Virol 2006; 16: 225-250.

25. Kawai K, Gebremeskel BG and Acosta CJ. Systematic review of incidence and complications of herpes zoster: Towards a global perspective. Brit Med J Open 2014; 4: e004833.

26. Blank LJ, Polydefkis MJ, Moore RD, et al. Herpes zoster among persons living with HIV in the current antiretroviral therapy era. J Acquir Immune Defic Syndr 2012; 61: 203-207.

27. Jansen K, Haastert B, Michalik C, et al. Incidence and risk factors of herpes zoster among HIV-positive patients in the german competence network for HIV/ AIDS (KompNet): A cohort study analysis. BMC Infect Dis 2013; 13: 372.

28. Amanna IJ, Carlson NE and Slifka MK. Duration of humoral immunity to common viral and vaccine antigens. N Engl J Med 2007; 357: 1903-1915.

29. Whitley RJ. Varicella-Zoster Virus infections. In: Longo DL, Kasper DL, Jameson JL, et al. (eds) Harrison's principles of internal medicine: Volumes 1 and 2. 18th ed. New York: McGraw-Hill Professional, 2011, pp. 1462-1466.

30. Gershon AA, LaRussa P and Steinberg SP. Varicella-zoster virus. In: Murray PR, Baron EJ, Pfaller MA, et al. (eds) Manual of clinical microbiology. 7th ed. Washington, DC: ASM Press, 1999, pp. 900-911.

31. Jansen K, Brockmeyer NH, Hahn M, et al. Epidemiological composition, clinical and treatment characteristics of the patient cohort of the German Competence Network for HIV/AIDS. Eur J Med Res 2009; 14: 415-425.

32. Stuke K, Flachenecker P, Zettl UK, et al. Symptomatology of MS: Results from the German MS Registry. J Neurol 2009; 256: 1932-1935.

33. Arvin AM and Prober CG. Herpes simplex viruses. In: Murray PR, Baron EJ, Pfaller MA, et al. (eds) 
Visit SAGE journals online http://msj.sagepub.com

(SAGE journals
Manual of clinical microbiology. 7th ed. Washington, DC: ASM Press, 1999, pp. 878-887.

34. Kangro $\mathrm{HO}$ and Harper DR. The Herpesviridae: Varicella zoster. In: Zuckerman AJ, Banatvala JE and Pattison JR (eds) Principles and practice of clinical virology. 3rd ed. Chichester: John Wiley and Sons, 1994, pp. 37-68.

35. Dobec M, Bossart W, Kaeppeli F, et al. Serology and serum DNA detection in shingles. Swiss Med Weekly 2008; 138: 47-51.

36. Sauerbrei A, Eichhorn U, Schacke M, et al. Laboratory diagnosis of herpes zoster. J Clin Virol 1999; 14: 31-36.
37. Weinberg A, Zhang JH, Oxman MN, et al. Varicellazoster virus-specific immune responses to herpes zoster in elderly participants in a trial of a clinically effective zoster vaccine. $J$ Infect Dis 2009; 200: 1068-1077.

38. Malavige GN, Rohanachandra LT, Jones L, et al. IE63-specific T-cell responses associate with control of subclinical varicella zoster virus reactivation in individuals with malignancies. Br J Cancer 2010; 102: 727-730

39. Birlea M, Arendt G, Orhan E, et al. Subclinical reactivation of varicella zoster virus in all stages of HIV infection. J Neurol Sci 2011; 304: 22-24. 